\title{
The History of Experience: Afterword
}

\author{
Josephine Hoegaerts and Stephanie Olsen
}

\section{New Traditions and New Voices}

The history of experience, in the novel ways that the authors of Lived Nation and the associated HEX research center are conceiving of it, is a new field, but one that builds upon strong historiographical traditions, especially the history of emotions. We point below to some of the spaces in which the history of experience can make a substantial contribution to existing fields including, of course, the history of the nation, but also the history of childhood and youth and the history of disability, among many others. The history of experience is concerned with embodied engagement with social, cultural, political and material contexts, in order to understand lived experiences through these engagements. It centers the (inter)subjectivity of discourses and practices of the past.

\footnotetext{
J. Hoegaerts $(\bowtie)$

University of Helsinki, Helsinki, Finland e-mail: josephine.hoegaerts@helsinki.fi

S. Olsen

Tampere University, Tampere, Finland
}

(C) The Author(s) 2021

V. Kivimäki et al. (eds.), Lived Nation as the History of Experiences and Emotions in Finland, 1800-2000, Palgrave Studies in the History of Experience, https://doi.org/10.1007/978-3-030-69882-9_15 
We have been asked to write this afterword to point to new directions for and applications of the history of experience. We do so, of course, from our own combined perspectives as historians of experience, of childhood and youth, of education, of gender, of the emotions and the senses as well as of sound and embodied practice. Giving space to historical sounds, voices and other nontextual sources has taught us to value the embodied character of communication and expression. Drawing upon deeper understandings of the (sensorial as well as emotional) experiences of historical actors as they forged ways to understand each other and live together is therefore essential to historical writing. The methodological frameworks explored in this book present important suggestions and challenges in this vein.

While most of the focus in this volume is on modern Finnish history, the conceptual and methodological tools developed, and the relevance to larger themes related to the "nation"-war, citizenship, patriotism, inclusion/exclusion, children and disability — point to a much broader applicability in future historiography. Authors in the volume demonstrate, in their respective chapters, the many intersections between themes, methodological approaches and subfields to which the history of experience can bring new insights. The pedigree of this new approach is also inherently international.

As showcased in many chapters of this book, the history of experience is often informed by the tools and concepts developed over the past 30 years in the history of emotions and senses. Emotions, senses and experiences are clearly linked and perhaps are mutually defined. ${ }^{1}$ Emotions and senses - the way they are shaped, felt and displayed-are part of what defines experience for both individuals and collectives. Experiences cannot be understood without them and are in a constant process of being reshaped because of them. In other words, the history of experience frees up historians of emotions to look less narrowly at what made humans what they were in the past (and relatedly, what makes them what they are in the present). ${ }^{2}$ It strives to incorporate human feelings and senses as part of a wider understanding of human experience-of what it meant, and means, to be human. It also underlines how being and feeling human is always

${ }^{1}$ Rob Boddice \& Mark Smith, Emotions, Sense, Experience (Cambridge: Cambridge University Press, 2020), chapters 3, 4 \& 5.

${ }^{2}$ See Joanna Bourke, What It Means to Be Human (London: Virago, 2011); Rob Boddice, A History of Feelings (London: Reaktion, 2019), 188-91. 
contextual, dependent on the changing material, cultural and structural features of our world.

The history of experience, therefore, offers new ways to include otherwise absent historical actors. Historians of experience decenter narrative and discourse, putting them in the context of worlds represented in, and constructed by, material, visual and audible sources. Through the history of the lived body, they seek to listen to otherwise hidden "voices" and to see otherwise hidden bodies. Or rather, they suggest ways to bypass the metaphor of the historical actor's voice and its ability to be "heard" completely. Frequently building on the methodologies of histories of emotions and the senses, analyses of experience not only point toward nontextual sources in new ways, but also displace language and speech as primary roads toward knowledge about the past. After all, if meaning-making in the past consisted of so much more than the articulation and the creation of text and imagery, histories, too, should move beyond logocentrism, and include a wider range of meaning-making practices. Not only seeing, understanding, knowing and writing, but also feeling, hearing, teaching, sensing and other modes of perceiving, including the vicissitudes of historical cognition, should figure in historical analysis.

In some ways, these moves toward the inclusion of practices (and the people carrying them out), that cannot easily be understood as "discourse," also open up new ways of reimagining the connections between cultural and social history and, above all, the role of "materialism" in both. Used as shorthand for both tangible and economic issues, "material" history often seems to move away from the particularity of human life; but as many scholars have shown, the physical, economic world and that of human senses and sensibilities have been, and are, deeply entangled. ${ }^{3}$ Histories of experience promise to insist on those entanglements rather than analytically to pick them apart, thus giving the single human a new place in societies of the past. Insisting on such material, experiential entanglements offer ways to break away from links and tension between individual and collective "identities" and to focus instead on how experiences can be shared (or not shared), can be "inner" or openly expressed, can be acceptable or unthinkable for a community.

\footnotetext{
${ }^{3}$ For example, Jennifer Tucker, "Visual and Material Cultures," in New Directions in Social and Cultural History, ed. by Sasha Handley, Rohan McWilliam \& Lucy Noakes (London: Bloomsbury, 2018); Donna Loftus, "Markets and Cultures," in Handley, McWilliam \& Noakes (2018).
} 
Seeking historical accounts of experience can, in very broad strokes, be juxtaposed with sources dealing with prescription or official attempts to shape lives. But this is an unhelpful dichotomy. In fact, the history of experience promises to afford us new ways to engage with source material we know very well-that of political, medical, educational and juridical institutions - and to find new ways of mobilizing this material to include historical actors whose "voice" may have been lost, but whose "experiences" we can at least partly come to know, thus enriching our understanding of the diversity of lived realities within or opposed to such institutions. The political structure of "the nation" has produced many such institutions, and their attendant bureaucracies and archives, and therefore offers a number of possibilities to enable such a shift of perspective and narrative.

What a history of experience might represent, therefore, is a way of disrupting grand narratives of what the past means. It not only taps into historiography's rich tradition of eclecticism, creating a space to adopt and adapt insights from other disciplines like cognitive science, anthropology, psychology and others, but it also has the potential to lend to those disciplines, challenging essentialism at every step.

\section{EXPERIENCING THE NATION}

Focus on the lived nation provides an excellent context in which histories of experience play out: a laboratory of human experience that has traditionally been approached as one of ideologies and collectives. This volume is a powerful, implicit critique of histories of "great men" and their archives and seeks to return to a focus on individuals from a radically different perspective. This methodological project goes beyond a micro-historical or biographical approach to history. Complex and abstract categories of a social or political nature also owe their "real" existence to their experiential presence in historical actors' lives. While "the nation" as an imagined community or collective is an ideological construct and a political agreement (and has been studied as such), it has come into being as a felt reality for citizens through experiences of belonging, and for noncitizens through experiences of exclusion. Writing histories of national awakening, consolidation, independence or isolation as histories of "lived nation" is therefore not just a matter of giving voice to different inhabitants of that nation, but also foregrounds the constant interplay between ideology and practice, or between subjective and intersubjective performances in the making of national realities. Attending to experience as a historical category, as this 
volume demonstrates, cuts across multiple approaches and subdisciplines, including those concerned with ideas and ideology, politics and institutions, memory and memorialization as well as those that bring historical bodies, sensations and feelings into focus.

As the reconfiguration of national history into one of a "lived nation" shows, the category of experience brings the historically contingent boundedness of ideologies, ideas and (political) discourses into view. Nations, like other modes of belonging, are not just "constructions" but also the result of a repeated range of concrete experiences through which nations are conjured up for those who "live" them. ${ }^{4}$ Nations are moored to particular spaces inhabited by the memories, feelings and bodies that create them. They are anchored in languages that allow for their expression and that tie them to speaking, thinking and feeling humans, and they are rehearsed through daily practices of public and domestic interaction.

\section{INTERSECTIONS}

In approaching the nation from a range of different perspectives, Lived Nation also gives us a glimpse into how the history of experience can contribute to the further development of a number of methodological questions and categories of analysis. Such developments can take us far beyond the realms of histories of nations and belonging. Imagining the potential extension of the history of emotions to some of the categories of analysis we engage with in our own research, we reflect below on the exciting (and perhaps daunting) possibilities for histories of disability and childhood, respectively.

\section{Disability}

In providing an interface for discursive and "material" reality, between collective and individual perspectives, histories of experience can especially be expected to contribute substantially to those subfields in which it has traditionally been difficult to make scarce sources speak beyond normative, institutionally sanctioned narratives. Several chapters in this volume show how the history of experience can help us delve into the lives and histories of traditionally disempowered inhabitants of institutions designed

\footnotetext{
${ }^{4}$ Josephine Hoegaerts, "Singing the Nation, Singing the Self," in Masculinity and Nationhood 1830-1910 (London: Palgrave Macmillan, 2014).
} 
to educate, cure or otherwise change them. The study of the history of disability has been grappling with such issues for almost four decades. ${ }^{5}$ Moving from a "medical model" of disability to, first, a "social" and, more recently, a "cultural" one, scholars and activists alike have shifted their attention from normative and disciplinary narratives of impediments in need of a cure toward a perspective that centers on a sociocultural world in need of more inclusive thinking. ${ }^{6}$ This change has been profound. It has allowed scholars to question existing modes of authority (who decides, for instance, what disability means if models of medically defined normality no longer apply?). It has led to a critical reframing of practices of "observation" as part of a wider culture of "staring" and, above all, has laid bare the ways in which "disability" is constructed through the creation of and insistence upon culturally particular norms. This medical model of disability is not an innocent project of charting diversity in "nature" but a historically specific framework that supports an ultimately eugenic project of "progress." Refusing the medical gaze that underpins it and replacing it with a culturally critical perspective has been a successful scholarly endeavor, but one that risks erasing individual, material bodies as well as the experiences lived through them. Reading institutional discourses "against the grain," as articulations of a normative framework that produces disability, avoids "staring," at the cost of making the objects of the gaze invisible altogether. Focusing on the experiences contained in the bodies under the medical gaze or normative stare, and the experiences coconstructed in the intersubjective spaces between (differently abled) bodies offers a promising avenue toward their inclusion in a cultural history of disability.

\section{Children and Childhood}

Several of the chapters in Lived Nation deal with histories of children and childhood. They discuss how children internalized ideas about the nation, with children themselves as integral parts of it. The dynamic relation of

\footnotetext{
${ }^{5}$ Henri-Jacques Stiker, Corps infirmes et société (Paris: Aubier, 1982).

${ }^{6}$ Patrick Devlieger, Beatriz Miranda-Galarza, Steven E. Brown \& Megan Strickfaden, eds, Rethinking Disability: World Perspective in Culture and Society (Ghent: Garant, 2016).

${ }^{7}$ Rosemary Garland-Thompson, Staring: How We Look (Oxford: Oxford University Press, 2009).
} 
individually and collectively lived experience is the target here. Modes of practicing collective emotions, of children living together through emotive prescriptions of childhood afford an avenue of inquiry, with a particular focus on how children experienced war and its aftermath. This pertains not merely to the presence or awareness of military conflict, but to their experience in navigating prescriptive attempts to educate them in ways specific to wartime. Education and enculturation are never neutral for children - they are always directed by the views and ideals of contemporary culture and society-and contexts of war provide stark settings in which these processes are particularly acute. Experts, parents and teachers might have conceived of the problem of wartime education as the shaping of emotions, mobilized by particular visions of the child as future citizen or embodiment of a national ideal, but rarely did children blindly follow prescription. The history of experience affords a more robust way to understand this complexity.

Historians of childhood and youth have been frustrated with the limited tools available to uncover historical actors' lived realities. ${ }^{8}$ How do we as historians access individual and collective humanity-the experiences, motivations, thoughts and feelings-of children and youth, who often leave few traces in the historical record? Those they do leave are often mediated adult recollections.

There is currently a historiographical imperative to downplay what adults thought and did about childhood and instead focus on children's "voices" and what they experienced themselves. This issue is even manifest in the division of the field itself into the history of childhood and the history of children. Broadly, the former focuses on top-down concepts of and prescriptions for childhood, and the latter focuses on children themselves. ${ }^{9}$

\footnotetext{
${ }^{8}$ Karen Vallgårda, Kristine Alexander \& Stephanie Olsen, "Emotions and the Global Politics of Childhood," in Childhood, Youth and Emotions in Modern History: Global, Imperial and National Perspectives, ed. by Stephanie Olsen (Basingstoke: Palgrave Macmillan, 2015), 12-34; Karen Vallgårda, Kristine Alexander \& Stephanie Olsen, Against Agency (Society for the History of Children and Youth, Internet publication, 2018), https://www. shcy.org/features/commentaries/against-agency/, accessed 8 September 2020.

${ }^{9}$ For introductions, see Colin Heywood, Childhood in Modern Europe (Cambridge: Cambridge University Press, 2018), 6-9; Mary Jo Maynes, "Age as a Category of Historical Analysis: History, Agency, and Narratives of Childhood," The Journal of the History of Childhood and Youth 1:1 (2008), 114-24.
} 
Yet this dichotomy is false when viewed through the lens of the history of experience. Even institutional and political sources, when read against the grain, can provide us with a new understanding of what it meant and felt like to be a child in a particular time and place, or at the very least how those feelings were framed. The inculcation in children of experiences of national belonging, resistance to national belonging, or even a sense of a nation in a process of change or conflict, all take place within prescriptive frameworks that either delimit experience or define when limits have been exceeded. While the question of the authenticity and reliability of historical narratives of past individuals and groups is perhaps especially relevant and particularly acute for historians of childhood and youth, it is, nonetheless, one that should be common for all historians. No experience occurs outside of a context.

\section{Boundaries of the New History of Experience}

While the history of experience promises to open new doors to understanding the past, it is decidedly not a history of everything. In its inherent multiplicity and fluidity, experience might look like a boundless, and therefore unwieldy, category. There are, however, clear limits to "experience." Or rather, it is clear what a history of experience is not. Histories of experience are not histories of ideas, events, actions or discourses as they might traditionally be understood, although they may of course intersect with and reimagine all of these concepts. Focused on the "lived reality" of historical actors, histories of experience push for a thick layering of accounts and meanings of the past, more than for an analysis predicated on "disentangling" particular constituent parts of historical structures or events. In that sense, a push toward experience also pushes us to imagine source criticism in new ways, and particularly invites us toward a rethinking of the authorial voice in many of our historical documents. The classical string of contextualizing questions-who, what, when, how-gains new meaning when we not only ask them of the practices of writing, or the events and ideas examined, but also involve the experiential world of both the writers and those about whom they write.

Lived Nation, through its focus on topics in modern histories of nation, has provided a template for other historians to "do" the new history of experience. Its diverse approach, embracing a wide range of analytical 
categories in conjunction with "experience," encourages us toward a historical approach that is inherently messy, entangled and complicated. Its agenda pushes us to look at primary sources in fresh ways and to ask fundamentally different questions of our source material. It is a new historiography in challenging times, a practice that reflects frustrations and inadequacies with previous approaches, while at the same time mobilizing new contemporary concerns.

Open Access This chapter is licensed under the terms of the Creative Commons Attribution 4.0 International License (http://creativecommons.org/licenses/ by $/ 4.0 /$ ), which permits use, sharing, adaptation, distribution and reproduction in any medium or format, as long as you give appropriate credit to the original author(s) and the source, provide a link to the Creative Commons licence and indicate if changes were made.

The images or other third party material in this chapter are included in the chapter's Creative Commons licence, unless indicated otherwise in a credit line to the material. If material is not included in the chapter's Creative Commons licence and your intended use is not permitted by statutory regulation or exceeds the permitted use, you will need to obtain permission directly from the copyright holder.

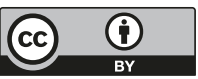

